\title{
Bayesian random effects modelling with application to childhood anaemia in Malawi
}

\author{
Alfred Ngwira ${ }^{1 *}$ and Lawrence N Kazembe ${ }^{2}$
}

\begin{abstract}
Background: Epidemiological studies in Malawi on child anaemia have neglected the community spatial effect to childhood anaemia. Neglecting the community spatial effect in the model ignores the influence of unobserved or unmeasured contextual variables, and at the same time the resultant model may under estimate model parameter standard errors which can result in erroneous significance of covariates. We aimed at investigating risk factors of childhood anaemia in Malawi with focus on geographical spatial effect.

Methods: We adopted a Bayesian random effect model for child anaemia with district as spatial effect using the 2010 Malawi demographic healthy survey data. We fitted the binary logistic model for the two categories outcome (anaemia $(\mathrm{Hb}<11)$, and no anaemia $(H \mathrm{~b} \geq 11))$. Continuous covariates were modelled by the penalized splines and spatial effects were smoothed by the two dimensional spline.
\end{abstract}

Results: Residual spatial patterns reveal Nsanje, Chikhwawa, Salima, Nkhota-kota, Mangochi and Machinga increasing the risk of childhood anaemia. Karonga, Chitipa, Rumphi, Mzimba, Ntchisi, and Chiradzulu reduce the risk of childhood anaemia. Known determinants such as maternal anaemia, child stunting, and child fever, have a positive effect on child anaemia. Furthermore childhood anaemia decreases with child age. It also decreases with wealth index. There is a $U$ relationship between child anaemia and mother age.

Conclusion: Strategies in childhood anaemia control should be tailored to local conditions, taking into account the specific etiology and prevalence of anaemia.

Keywords: Binary logistic model, Structured additive, Geo-additive, P-splines

\section{Background}

Childhood anaemia is a global public health problem. According to World Health Organization (WHO) current report on world prevalence of anaemia [1], the global prevalence of anaemia is $24.8 \%$ with the highest prevalence in preschool-age children (47.4\%). Regional WHO estimates of childhood anaemia shows subSaharan Africa (SSA) having the highest prevalence, about 67\%, seconded by the South East Asia (65.5\%). The latest report though by [2] on world prevalence of anaemia shows that world prevalence of anaemia for preschool-age children has decreased from $47 \%$ to $43 \%$ and that South Asia, Central and West Africa have the highest prevalence. Malawi, part of the sub-Saharan Africa and in Central Africa has 63\% prevalence of childhood

\footnotetext{
* Correspondence: alfngwira@yahoo.com

${ }^{1}$ Department of Mathematical Sciences, University of Malawi, Chancellor College, Zomba, Malawi

Full list of author information is available at the end of the article
}

anaemia according to the 2010 Malawi Demographic Health Survey (MDHS) report [3]. Consequences of the childhood anaemia are poor cognitive development for mild and moderate anaemia, and death for severe anaemia. Severe anaemia carries a significant risk of death by profound hypoxia and congestive heart failure, or more rarely, by cerebral malaria $[4,5]$.

Epidemiology of childhood anaemia shows multifactorial risk factors. About $50 \%$ of all anaemia cases are due to iron deficiency [6]. Other micronutrients, such as vitamin A, vitamin $\mathrm{C}$, and folate are important in the pathophysiology of anaemia. Infections such as malaria, HIV, bacteraemia caused by organisms such as Steptococcus pneumoniae, non-typhi Salmonella species, and Haemophilus influenzae type $b$, and helminth infections caused by hookworm and Schistosoma haematobium are also known to cause anaemia $[7,8]$. The general mechanisms by which these infections lead to 
anaemia include blood loss, sequestration of red blood cells by the spleen, haemolysis by antibodies, and anaemia of inflammation (via TNF-alpha and IL-6 production). Previous studies have also shown that socioeconomic factors such as low parental education levels [9], low household incomes, and demographic factors including age, sex [10], and family size [11] affect anaemia. Sickle cell disease has also been recognized as an important risk factor for anaemia in subSaharan countries [12].

To our knowledge, studies on childhood anaemia in Malawi have not assessed the geographical heterogeneity in childhood anaemia causes $[7,13]$. The ignorance of heterogeneity in models according to [14], may lead to biased parameter estimates. But more importantly, geographical heterogeneity can be an effect of unmeasured covariates which may include contextual factors. That is, geographical differences in the causes of anaemia can be partially explained by large-scale variability in environmental drivers, particularly nutritional and infectious causes. Malaria as an infectious cause of anaemia is known to be associated with elevation and land surface temperature. Similarly, nutritional iron deficiency and anaemia-causing helminth infections are known to be associated with the distance to a perennial water body, land surface temperature and the normalized difference vegetation index (NDVI). The environmental drivers of anaemia tend to show a high degree of spatial dependence (i.e. geographical clustering) $[15,16]$. There are number of studies though outside Malawi [17-21], that have taken into account the geographical heterogeneity in modelling of anaemia, but all these studies have often ignored the flexible approach of using bivariate splines in modelling geographical heterogeneity.

The study of geographical heterogeneity of a health outcome can benefit from the multilevel or spatial mixed model. For example $[18,20,21]$, use a multilevel model and $[17,19]$ use a spatial mixed model. In multilevel models geographical heterogeneity is modelled as a random effect and geographical variation in the outcome variable is assessed via variance partition coefficient (VPC) or intra-class correlation coefficient (ICC). In spatial mixed models, geographical heterogeneity of an outcome is assessed by specifying a spatial correlation structure for individual residuals. A comparison study of a multilevel and a spatial mixed model for investigating place effects on health outcomes by [22] showed a smaller deviance for spatial mixed model than a multilevel model, and that the Moran's I statistic showed residual spatial autocorrelation unaccounted for by the multilevel model.

Spatial mixed models have been widely used to asses the geographical effect on an outcome ([17,19,23-26], among others). In case of areal data, where individual information for areas is provided, spatial lattice models, which usually consider correlation between adjacent areas of a territory, are considered appropriate. If the data has location coordinates (latitude and longitude or centroids based on the map), then use of a geo-statistical model proves appropriate. In this study for example, there was no individual information for all districts, but districts centroids based on the map could be got. Thus a geo-statistical model either based on kriging or bivariate spline was appropriate [22].

The contribution of this study would be the application of the spatial mixed model in assessing the significance of correlated geographic effect on childhood anaemia which has not been extensively done by assuming the flexible approach of bivariate splines. Furthermore the study would be the first ever to map childhood anaemia in Malawi in terms of residual spatial effects. The map would have important implications for targeting policy as well as the search for left-out variables that might account for these residual spatial patterns.

\section{Methods}

\section{Study area and data}

The study focused on Malawi and used the standard and nationally representative 2010 Malawi Demographic and Health Survey (MDHS) data. The MDHS data was downloaded from the DHS website (http://www.measuredhs. com/login.cfm) after being granted permission. The sampling design was a two stage cluster design with stratification. The primary sampling units were the enumeration areas (EAs), and the secondary sampling units were the households. EAs were stratified in terms of rural and urban. A total of 849 EAs were sampled with 158 in urban areas and 691 in rural areas. A representative total sample of 27345 households was selected for the 2010 MDHS survey. Data collection was by questionnaires. There were three questionnaires, women, men and household questionnaire. Households that were successfully interviewed were 24825 , yielding a response rate of $98 \%$. Eligible women that were successfully interviewed were 23020, yielding response rate of $97 \%$. Eligible men that were successfully interviewed were 7175 , yielding a response rate of $92 \%$. The data set that was used in this study was child record data set which was based on women and household questionnaire. The child record data set had a total of 19967 children records. The following exclusion criteria based on 2010 MDHS report [3] and MDHS guide to statistics [27] was used to have the final sample for children. Children whose mothers were not listed in the household questionnaire were not included. All children records where haemoglobin level was missing were dropped. The missing covariate values were left unremoved. The final sample size of children was thus 4177 . 
Data management in terms of extracting and generation of variables from child record data set was done in STATA version 12. Data variables used in this study were based on the variables used in previous studies on childhood anaemia. Response variable in the extracted data set was child anaemia status based on the categorization of child altitude adjusted haemoglobin level. Child anaemia status was a binary variable based on the cut off point of $11 \mathrm{Hb}$. Children whose haemoglobin level was less than $11 \mathrm{Hb}$ were taken as anaemic and not anaemic otherwise. The cut off point used in classifying child anaemia into two categories was based on 2010 MDHS report. The covariates in the generated data set were mother education level, family wealth index, child cough, child fever, receiving vitamin A, mother anaemia status, stunting, wasting, underweight, child birth weight, child birth order, house hold size, child age in months, mother age in years, whether child ate meat in previous one month or not, breast feeding in months and district of the child. Child age in months, mother age in years and breast feeding in months were continuous covariates. Stunting, wasting and underweight were based on categorization of height for age, weight for height, and weight for age $\mathrm{z}$-scores respectively using $\mathrm{z}$-score -2 as cut off point. District of the child was labelled $s_{i} \epsilon(1,2,3, . ., S)$ where the label was corresponding to label on the map.

\section{Statistical analysis}

Univariate logistic regression was performed in STATA statistical software, version 12 to select potential factors of childhood anaemia. Covariates that were associated with anaemia at significance level of $20 \%$ were incorporated in the multiple regression models. The significant level of $20 \%$ rather than $5 \%$ was used in selecting covariates for multiple regression analysis so as to allow more potential covariates to be selected. Two way cross tabulation was then performed in STATA statistical software, version 12 to find percentage distribution of childhood anaemia per district and per covariate categories. Percentages were weighted using the sampling weight to ensure representative sample. The two way cross tabulation with Pearson chi-square $\left(\mathcal{X}^{2}\right)$ test was used to compare groups of categorical variables.

Four multiple logistic models were then fitted using R2BayesX package in software $\mathrm{R}$ using child anaemia status as a response. More formally, considering child anaemia status being binary, in this case child anaemia status being distributed as Bernoulli $\left(p_{i j}\right)$ where $p_{i j}$ is the probability of child $j$ being anaemic in location $i$, the following models were fitted.

Model 1: $\operatorname{logit}\left(p_{i j}\right)=w_{i}^{T} \gamma$
Model 2: $\operatorname{logit}\left(p_{i j}\right)=w_{i}^{T} \gamma+f_{1}\left(x_{i 1}\right)+f_{2}\left(x_{i 2}\right)_{+} . .+f_{p}\left(x_{i p}\right)$

Model 3: $\operatorname{logit}\left(p_{i j}\right)=w_{i}^{T} \gamma+f_{\text {spat }}\left(s_{i}\right)$

Model 4: $\operatorname{logit}\left(p_{i j}\right)=w_{i}^{T} \gamma+f_{1}\left(x_{i 1}\right)+f_{2}\left(x_{i 2}\right)+\ldots+f_{p}$ $\left(x_{i p}\right)+f_{\text {spat }}\left(s_{i}\right)$

Model 1 was a fixed effects variable model where all variables, categorical and continuous were modelled as fixed effects. In Model 2, categorical variables were modelled as fixed effects and continuous variables were modelled non parametrically by smooth function $f_{j}$ s. In Model 3 all covariates were modelled as fixed effects and district of the child was modelled as a spatial effect. Model 4 was an extension of Model 2 by including a spatial component. In the models, the smooth functions $f_{j}$ were specified as Bayesian splines. According to [28], this assumes approximating $f_{j}$ by polynomial splines of degree $l$ defined at equally spaced knots $x_{j}^{\text {min }}=\zeta_{j 0}, \zeta_{j 1}, \ldots, \zeta_{j s}=x_{j}^{\text {max }}$ which are within the domain of the covariate $x_{j}$. The Bayesian spline can be written as a linear combination of $d=s+l$ basis functions, $B_{m}$, that is,

$$
f_{j}\left(x_{j}\right)=\sum_{m=1}^{d} \varepsilon_{j m} B_{m}\left(x_{j}\right)
$$

Now Bayesian estimation of the penalized spline (1) is equivalent in estimating model parameters $\varepsilon_{j}=\left(\varepsilon_{j, 1}\right.$, $\left.\varepsilon_{j, 2}, \ldots, \varepsilon_{j, m}\right)$ where first or second order random walk priors for the regression coefficients are assigned. A first order random walk prior for equidistant knots is given by: $\varepsilon_{j, m}=\varepsilon_{j, m-1}+u_{j, m}$ where $m=2,3, \ldots, d$, and a second order random walk prior for equidistant knots is given by: $\varepsilon_{j, m}=2 \varepsilon_{j, m-1}+\varepsilon_{j, m-2}+u_{j, m}$ where $m=3,4, \ldots, d$ and $u_{j . m} \sim N\left(0, \tau_{j}^{2}\right)$ are random errors. The spatial effect was modelled by the tensor product of two dimensional spline defined as

$$
f_{\text {spat }}\left(x_{1}, x_{2}\right)=\sum_{i}^{k} \sum_{j}^{k} B_{\text {spat }, i j} B_{1 i}\left(x_{1}\right) B_{2 j}\left(x_{2}\right)
$$

where $\left(x_{1}, x_{2}\right)$ refers to the coordinates of the location of the data point, latitude and longitude, or location centroids based on the map. The prior for $B_{\text {spat, } i j}=\left(B_{\text {spat }, 11}\right.$, $\left.B_{\text {spat }, 12}, \ldots, B_{\text {spat }, k k}\right)$ is based on spatial smoothness priors common in spatial statistics (see [29]). The most commonly used prior specification based on the four nearest neighbours is defined as:

$$
\begin{aligned}
B_{\text {spat }, i j} \mid . \sim N\left(B_{\text {spat }, i-1 j}\right. & +B_{\text {spat }, i+1, j}+B_{\text {spat }, i, j-1} \\
& \left.+B_{\text {spat }, i, j+1}, \frac{\tau_{i j}^{2}}{4}\right)
\end{aligned}
$$

for $i, j=2, \ldots, k-1$ with appropriate changes for corners and edges. Since model estimation was by empirical Bayesian method, all variance parameters were treated as unknown constants that were estimated by restricted 
maximum likelihood (REML) method and hence their priors were not given. The fixed effects were assigned diffuse priors. An advantage of the empirical Bayesian inference over full Bayesian inference is that questions about the convergence of MCMC samples or sensitivity on hyper parameters do not arise [30]. Further more, a comparison of full Bayesian and empirical Bayesian approach in a simulation study, has shown empirical Bayesian approach yielding somewhat better point estimates, especially for Bernoulli distributed responses (see [31]).

\section{Results}

\section{Descriptive results}

Table 1 presents prevalence of childhood anaemia by region. Northern region is generally less anaemic compared to the central and southern region. Districts in the central region with relatively higher prevalence of childhood anaemia are Salima and Nkhota-kota with about $80 \%$ and $74 \%$ prevalence respectively. In the south, Chikhwawa, Nsanje, Balaka, Neno, Mangochi and Machinga have relatively higher prevalence of childhood anaemia. In the northern region, Nkhata-bay has relatively high prevalence of childhood anaemia with prevalence of about $73 \%$.

Table 2 shows the burden of childhood anaemia by categorical covariates and group comparison by Pearson chi-square tests. Males have almost the same prevalence of childhood anaemia as females. Also children of rural areas have higher prevalence of childhood anaemia compared to those of the urban. Childhood anaemia prevalence decreases with wealth. Childhood anaemia decrease from no education mothers to secondary education mothers and then increase for the mothers with higher education. Childhood anaemia prevalence increases with cough and fever. Vitamin A is seen as important in reducing childhood anaemia prevalence. Childhood anaemia prevalence also increases with childhood under nutrition. The categorical variables associated with childhood anaemia at 0.05 significance level without controlling for other factors are residence, wealth, mother education, mother anaemia status, underweight, stunting, wasting, cough, fever, and vitamin A. All categorical covariates in Table 2 were included in the multiple logistic models except the house hold size, ate meat, and child birth order number because their Pearson chi-square p-values are more than 0.2 .

\section{Empirical Bayesian results Model selection}

The choice of the better model is based on Alkaike Information Creterion(AIC) and the Generalized Cross Validation(GCV) as used by [32] when they used empirical Bayesian method in estimation of the STAR model. A model with the smallest AIC and GCV is considered
Table 1 Prevalence of childhood anaemia by district

\begin{tabular}{|c|c|}
\hline Region/district & \%Anaemic (total) \\
\hline Northern region & $58.71(728)$ \\
\hline Chitipa & $52.42(189)$ \\
\hline Karonga & $54.31(179)$ \\
\hline Nkhata-Bay & 72.89 (117) \\
\hline Rumphi & 56.78 (113) \\
\hline Mzimba & $59.98(130)$ \\
\hline Central region & $64.21(1,560)$ \\
\hline Kasungu & $68.78(198)$ \\
\hline Nkhota-Kota & $74.82(181)$ \\
\hline Ntchisi & $55.83(177)$ \\
\hline Dowa & $65.37(187)$ \\
\hline Salima & 80.62 (139) \\
\hline Lilongwe & $58.39(211)$ \\
\hline Mchinji & 61.19 (179) \\
\hline Dedza & $65.83(125)$ \\
\hline Ntcheu & $60.01(163)$ \\
\hline Southern region & $64.11(1,889)$ \\
\hline Mangochi & $73.40(160)$ \\
\hline Machinga & $75.24(141)$ \\
\hline Zomba & $62.75(165)$ \\
\hline Chiradzulu & 44.85 (116) \\
\hline Blantyre & $47.68(143)$ \\
\hline Mwanza & $64.83(121)$ \\
\hline Thyolo & $54.42(148)$ \\
\hline Mulanje & $60.96(121)$ \\
\hline Phalombe & 60.65 (190) \\
\hline Chikwawa & $78.52(150)$ \\
\hline Nsanje & 72.29 (163) \\
\hline Balaka & 70.39 (139) \\
\hline Neno & $72.76(132)$ \\
\hline
\end{tabular}

Row \% of child anaemia by district based on child data. MDHS 2010 (weighted).

as a better model. The AIC and GCV (Table 3) favours the geo-additive model, that is, Model 4, since it has the smallest AIC and GCV. Discussion of the results will therefore be based on Model 4, the geo-additive model.

\section{Fixed effects}

Fixed effects variables found to be significant to childhood anaemia (Table 3) are fever, wealth family of richest category, stunting and mother anaemia status. The coefficient for fever is positive which means children who have fever have increased risk to childhood anaemia compared to children who have no fever. Children of richest family have reduced risk to childhood anaemia than those who belong to poorest family, since the 
Table 2 Prevalence of childhood anaemia by categorical covariates and bivariate Pearson chi-square test $p$-values

\begin{tabular}{lll}
\hline Variable & \%Anaemic (total) & Pearson chi-square (P-value) \\
\hline Sex & & $2.45(0.117)$ \\
Male & $64.33(2,092)$ & \\
Female & $62.83(2085)$ &
\end{tabular}

Female

$17.50\left(0.000^{*}\right)$

Residence

$53.15(402)$

Rural

65.35 (3775)

Wealth

Poorest

$70.79(829)$

Poor

$65.77(964)$

Rich

$66.55(973)$

Richer

61.729 (813)

Richest

$51.88(598)$

Mother education

No education

Primary

Secondary

higher

House hold size

$\leq 5$

$>5$

Fever

No fever

With fever

Ate meat

No

Yes

\section{Cough}

No cough

With cough

VitaminA

No

Yes received

Stunting

No

Yes

\section{Wasting}

No

Yes

Underweight

No

yes

Mother anaemia
67.07 (714)

$64.17(2,917)$

$56.1(535)$

$79.03(11)$

$20.31\left(0.000^{*}\right)$

$0.68(0.410)$

$64.42(1,892)$

$62.81(2,285)$

$60.31\left(0.000^{*}\right)$

$59.39(2,738)$

$67.33(2,666)$

71.45 ( 465)

$9.68(0.002 *)$

$61.61(2,974)$

$69.06(1,171)$

$66.46(527)$

$63.05(3,643)$

$21.55\left(0.000^{*}\right)$

$60.5(2,256)$

$67.02(1,714)$

$16.63(0.000 *)$

$62.7(3,819)$

79.99 (152)

$18.40\left(0.000^{*}\right)$

$61.85(3,232)$

$69.93(738)$

$34.35\left(0.000^{*}\right)$
Table 2 Prevalence of childhood anaemia by categorical covariates and bivariate Pearson chi-square test $\mathbf{p}$-values (Continued)

\begin{tabular}{|c|c|c|}
\hline No & $62.09(3,510)$ & \\
\hline Yes & 73.11 (577) & \\
\hline Birth Order & & $1.84(0.606)$ \\
\hline 1 & 64.25 (769) & \\
\hline $2-3$ & $62.84(1,504)$ & \\
\hline $4-5$ & $62.49(1,058)$ & \\
\hline $6+$ & $65.72(846)$ & \\
\hline
\end{tabular}

coefficient for the richest family is negative. Coefficient for stunting is positive, which means stunted children have a higher risk of childhood anaemia compared to children who are not stunted. Mother anaemia status has a positive effect to childhood anaemia, that is, children of anaemic mothers have their risk to childhood anaemia more than children whose mothers are not anaemic.

\section{Non linear effects}

Months of breast feeding has an insignificant non linear effect to childhood anaemia (Figure 1) since the variance parameter for the effect of months of breast feeding is zero (Table 3) which means assumption of non linearity does not hold. As a matter of fact the effect of months of breast feeding is linear with childhood anaemia decreasing as months of breast feeding increases.

Child age has somewhat significant non linear effect to childhood anaemia (Figure 2) since the variance parameter for the effect of child age is not zero (Table 3). As child age increases, its effect on child anaemia decreases, that is, older children are less likely to have childhood anaemia. The chance of having anaemia is much higher in children aged about 6 months to about 20 months and decreases there after.

Mother age has a significant non linear effect to childhood anaemia (Figure 3) since the variance parameter for its effect is not zero (Table 3). There is a $U$ functional relationship between childhood anaemia and mother age. Young mothers are more likely to have children who are anaemic; in particular mothers aged 15 years to about 25 years. The risk to childhood anaemia remains reduced for mothers aged 22 to about 40 years. Childhood anaemia risk then rises for mothers who are aged 40 years and above.

\section{Spatial effects}

Spatial effects are surrogates of unknown influences, for example climatic and environmental factors, access to good transport system, and access to good child health 
Table 3 Summary of four binary logistic models

\begin{tabular}{|c|c|c|c|c|}
\hline Variable & $\begin{array}{l}\text { Model } 1 \\
\text { Coeffecient } \\
(95 \% \mathrm{Cl})\end{array}$ & $\begin{array}{l}\text { Model } 2 \\
\text { Coeffecient } \\
(95 \% \mathrm{Cl})\end{array}$ & $\begin{array}{l}\text { Model } 3 \\
\text { Coeffecient } \\
(95 \% \mathrm{Cl})\end{array}$ & $\begin{array}{l}\text { Model } 4 \\
\text { Coeffecient } \\
(95 \% \mathrm{Cl})\end{array}$ \\
\hline Constant & $2.236^{*}(1.7302 .742)$ & $0.781^{*}(0.4541 .107)$ & $2.081^{*}(1.4952 .666)$ & $0.597^{*}(0.1641 .030)$ \\
\hline \multicolumn{5}{|l|}{ Residence } \\
\hline Rural & - & - & - & - \\
\hline Urban & $-0.206(-0.4650 .053)$ & $-0.193(-0.4530 .068)$ & $-0.118(-0.3950 .158)$ & $-0.104(-0.3810 .173)$ \\
\hline \multicolumn{5}{|l|}{ Child sex } \\
\hline Female & - & - & - & - \\
\hline Male & $0.068(-0.0750 .211)$ & $0.066(-0.0770 .209)$ & $0.085(-0.0610 .228)$ & $0.080(-0.0650 .224)$ \\
\hline \multicolumn{5}{|l|}{ Mother education } \\
\hline No education & - & - & - & - \\
\hline Primary & $-0.275^{*}(-0.486-0.065)$ & $-0.275^{*}(-0.485-0.065)$ & $-0.116(-0.3340 .101)$ & $-0.118(-0.3350 .099)$ \\
\hline Secondary & $-0.372^{*}(-0.667-0.076)$ & $-0.369^{*}(-0.666-0.072)$ & $-0.190(-0.4930 .113)$ & $-0.192(-0.4970 .112)$ \\
\hline Higher & $0.258(-1.1241 .640)$ & $0.254(-1.1351 .642)$ & $0.453(-0.9101 .817)$ & $0.436(-0.9361 .808)$ \\
\hline \multicolumn{5}{|l|}{ Wealth index } \\
\hline Poorest & - & - & - & - \\
\hline Poor & $-0.154(-0.3800 .071)$ & $-0.147(-0.3730 .079)$ & $-0.153(-0.3820 .076)$ & $-0.148(-0.3770 .082)$ \\
\hline Rich & $-0.137(-0.3640 .090)$ & $-0.139(-0.3660 .089)$ & $-0.122(-0.3530 .110)$ & $-0.122(-0.3550 .110)$ \\
\hline Richer & $-0.223(-0.4590 .014)$ & $-0.215(-0.4520 .021)$ & $-0.207(-0.4490 .035)$ & $-0.199(-0.4420 .043)$ \\
\hline Richest & $-0.475^{*}(-0.753-0.197)$ & $-0.468^{*}(-0.747-0.189)$ & $-0.489^{*}(-0.775-0.203)$ & $-0.481^{*}(-0.768-0.194)$ \\
\hline \multicolumn{5}{|l|}{ Fever } \\
\hline No & - & - & - & - \\
\hline Yes & $0.454^{*}(0.2860 .621)$ & $0.449^{*}(0.2810 .617)$ & $0.448^{*}(0.2770 .620)$ & $0.442^{*}(0.2700 .614)$ \\
\hline \multicolumn{5}{|l|}{ Cough } \\
\hline No & - & - & - & - \\
\hline Yes & $-0.013(-0.1870 .161)$ & $-0.019(-0.1940 .156)$ & $0.035(-0.1430 .213)$ & $0.028(-0.1510 .207)$ \\
\hline \multicolumn{5}{|l|}{ Vitamin A } \\
\hline No & - & - & - & - \\
\hline Yes & $-0.154(-0.3770 .069)$ & $-0.117(-0.3410 .107)$ & $-0.118(-0.3460 .110)$ & $-0.082(-0.3110 .147)$ \\
\hline \multicolumn{5}{|l|}{ Stunting } \\
\hline No & - & - & - & - \\
\hline Yes & $0.265^{*}(0.1070 .422)$ & $0.288^{*}(0.1290 .446)$ & 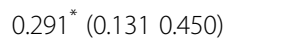 & $0.314^{*}(0.1530 .474)$ \\
\hline \multicolumn{5}{|l|}{ Underweight } \\
\hline No & - & - & - & - \\
\hline Yes & $0.108(-0.1030 .318)$ & $0.100(-0.1100 .310)$ & $0.102(-0.1110 .315)$ & $0.098(-0.1150 .311)$ \\
\hline \multicolumn{5}{|l|}{ Wasting } \\
\hline No & - & - & - & - \\
\hline Yes & $0.331(-0.1070 .768)$ & $0.324(-0.1160 .764)$ & $0.315(-0.1280 .759)$ & $0.309(-0.1360 .755)$ \\
\hline \multicolumn{5}{|l|}{ Mother anaemia } \\
\hline No & - & - & - & - \\
\hline Yes & $0.681^{*}(0.4610 .901)$ & $0.686^{*}(0.4660 .906)$ & $0.601^{*}(0.3770 .824)$ & $0.605^{*}(0.3820 .828)$ \\
\hline Child age & $-0.034^{*}(-0.040-0.029)$ & & $-0.035^{*}(-0.041-0.029)$ & \\
\hline Months of breast feeding & $-0.012(-0.0250 .000)$ & & $-0.013(-0.025-0.001)$ & \\
\hline Mother age & $-0.004(-0.0150 .008)$ & & $-0.003(-0.0150 .008)$ & \\
\hline
\end{tabular}


Table 3 Summary of four binary logistic models (Continued)

\begin{tabular}{|c|c|c|c|c|}
\hline \multicolumn{5}{|c|}{ Variance Components } \\
\hline Spatial effect & & & 0.6348 & 2.275 \\
\hline \multicolumn{5}{|l|}{ Non-linear effects } \\
\hline Child age $\tau_{\mathrm{c}}^{2}$ & & 0.115 & & 0.119 \\
\hline Mother age $\tau_{\mathrm{m}}^{2}$ & & 0.128 & & 0.147 \\
\hline Breast Feeding $\tau_{\text {bf }}^{2}$ & & 0.000 & & 0.000 \\
\hline \multicolumn{5}{|l|}{ Model fit } \\
\hline $\mathrm{AIC}$ & 4461.33 & 4443.66 & 4402.42 & 4386.81 \\
\hline GCV & 1.20699 & 1.20258 & 1.18882 & 1.18489 \\
\hline
\end{tabular}

Model 1(fixed effects), Model 2(fixed plus non linear effects), Model 3(fixed and spatial effects), and Model 4(geo-additive). _ means reference category, and * means significant at $5 \%$ significance level.

care services. These unknown factors may have a localized effect or global effect. Figure 4 presents total residual spatial effects to childhood anaemia. There is evidence of residual spatial effects to childhood anaemia in Malawi with Chikwawa, Nkhota-kota and Salima showing significant positive effects while Karonga and Chiradzulu show negative effects with regard to the $95 \%$ posterior credible intervals map (Figure 5). For the $80 \%$ posterior credible intervals map, Nkhota-kota, Salima, Chikhwawa, Nsanje, Mangochi and Machinga have significant positive effects while Karonga, Chitipa, Rumphi, Mzimba, Ntchisi, and Chiradzulu have significant negative effects (Figure 6).

\section{Discussion}

This study employed the use of geo-additive logistic model to study the relationship between childhood

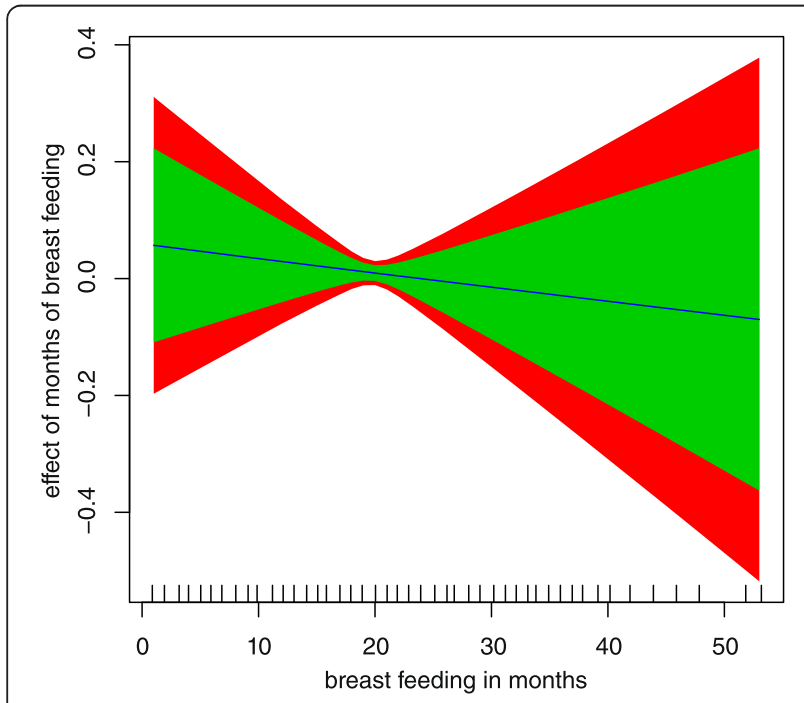

Figure 1 Non linear effect of months of breast feeding to childhood anaemia. Green band (80\% Cl), and red (95\% Cl). anaemia and its risk factors. The geo-additive model allowed the mapping of residual spatial effects to childhood anaemia while accounting for non-linear covariate effects under the assumption of additiviness. Modelling of metrical continuous covariates non linearly revealed their subtle influences that could not be observed when modelled linearly. The incorporation of spatial effect in the models made some covariates not to be significant anymore. For example, mother education primary and secondary level coefficients were found to be significant in Model 1 and Model 2 (Table 3) where there was no spatial effect, but were not significant in Model 3 and Model 4 (Table 3) when the spatial effect was included in the models. Actually, the spatial component in Model 3 and Model 4 according to [28] helped to avoid underestimate model parameter standard errors which could result in significance of the covariates.

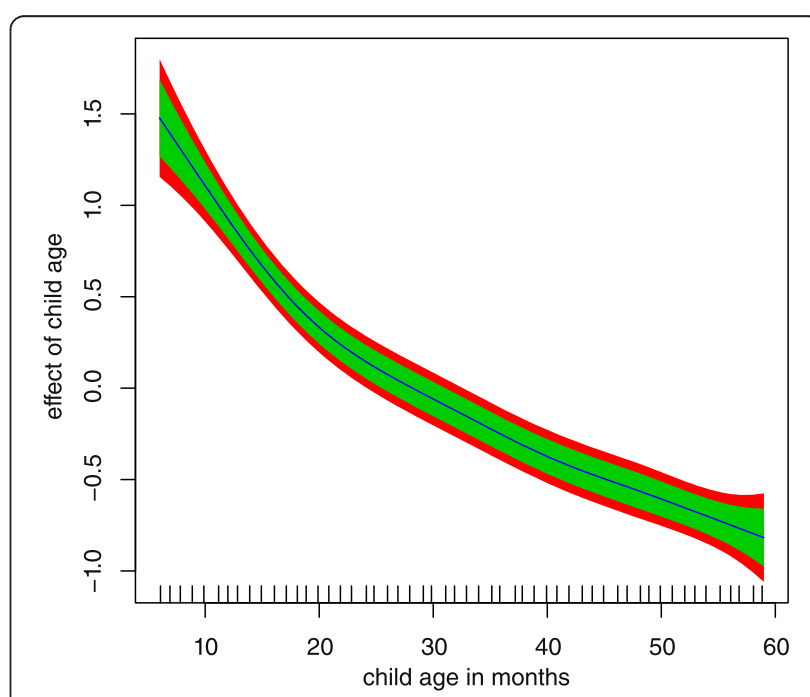

Figure 2 Non linear effect of child age to childhood anaemia. Green band $(80 \% \mathrm{Cl})$, and red $(95 \% \mathrm{Cl})$. 


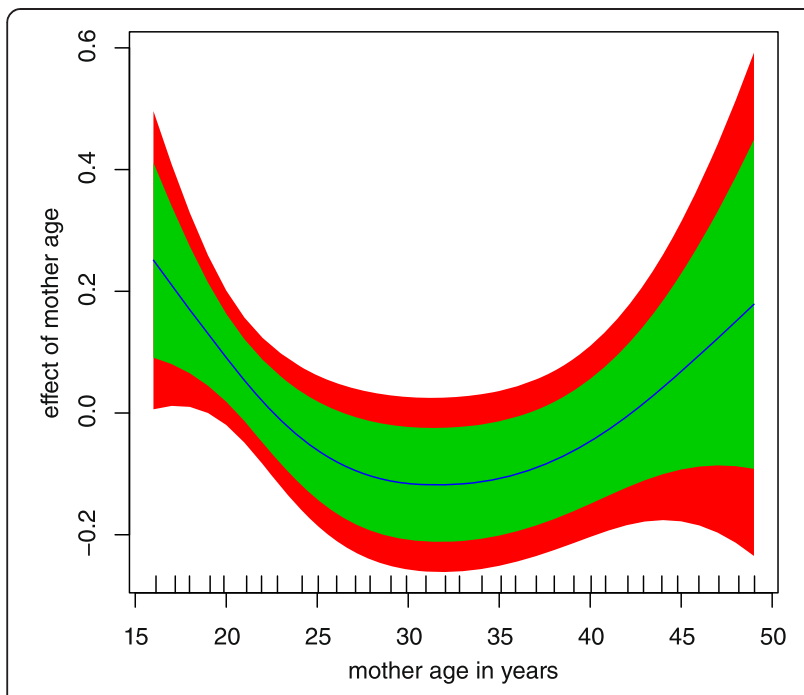

Figure 3 Non linear effect of mother age to childhood anaemia. Green band $(80 \% \mathrm{Cl})$, and red $(95 \% \mathrm{Cl})$.

The observed residual spatial pattern in childhood anaemia shows most districts in the north reducing child anaemia, and the districts that increased risk of anaemia were all close to water bodies. The observed spatial heterogeneity may be due to unobserved factors not captured by the covariates in the models, and it is a matter of conjecture to identify them. Geographical difference in anaemia-causing infections, like malaria, hook worms and helminths could be one cause of such spatial variation. Malaria is common in places close to water bodies and where temperatures are high (above 21\%). According to [33], the optimum temperature for mosquitoes development is between 22 and $32^{\circ} \mathrm{C}$. Similarly, soil moisture and relative atmospheric humidity are also known to influence the development and survival of ova and larvae for hookworms and helminths, where higher humidity is associated with faster development of ova [34,35]. Salima, Nkhota-kota, Mangochi, Machinga showed positive spatial effect to anaemia at $20 \%$ significance level probably due to lake Malawi, Lake Malombe, Lake Chiuta and Lake Chilwa, and Shire River which enhance the development of mosquitoes, hookworms and helminths. Transmission of hookworms and helminths along such water bodies would also be facilitated by open faecal disposal according to [36], since along these water bodies, open faecal disposal is common particularly by fisher men. Similarly, Nsanje and Chikhwawa districts had a positive effect to child anaemia probably because they are characterised by permanent wetlands (Ndindi and Elephant marsh) with large stretches of stagnant water, and that their temperatures are above $21^{\circ} \mathrm{C}$ which provide the best ground for the mosquitoes to breed, resulting in increased malarial transmission and let alone malaria anaemia.

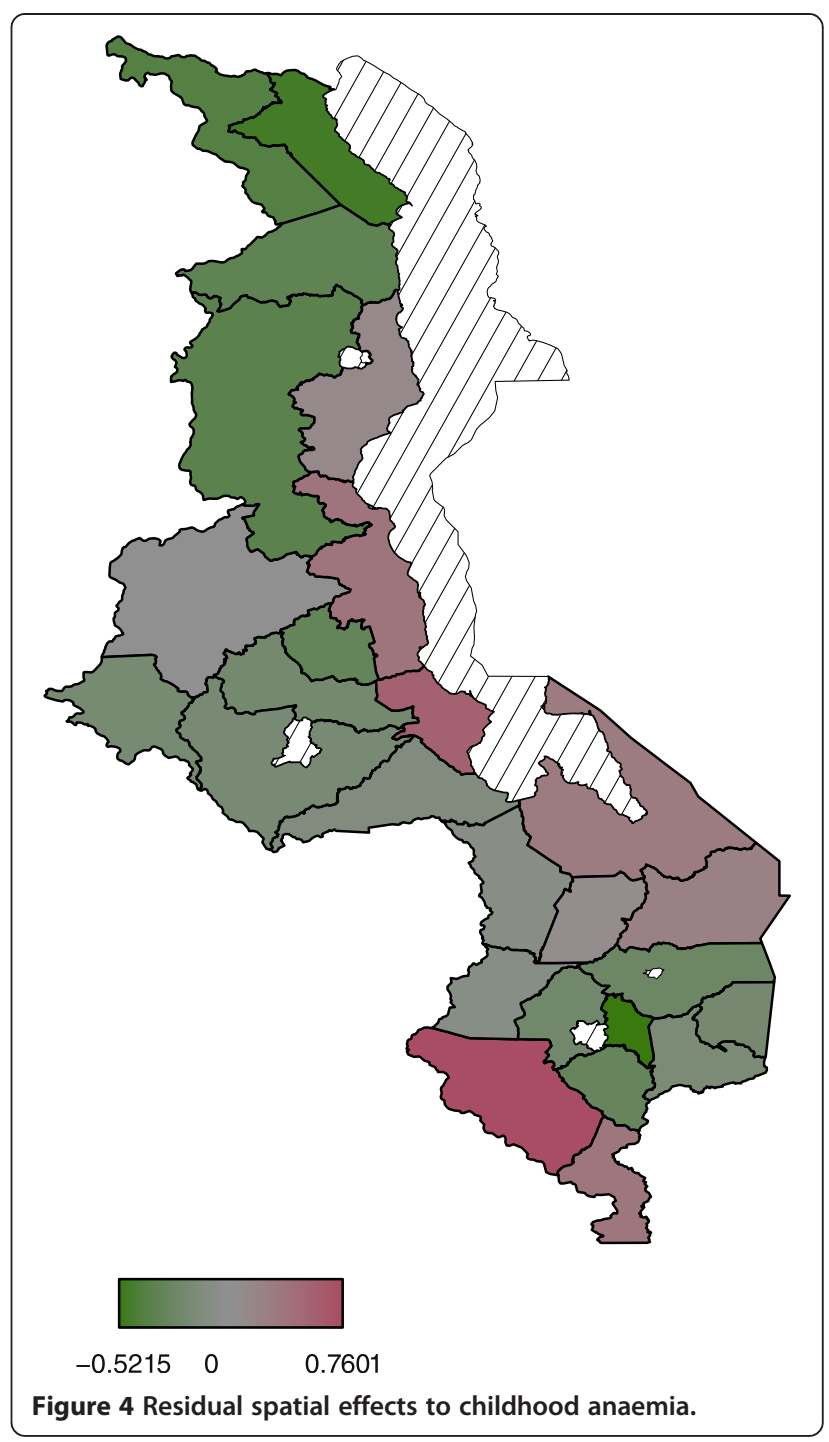

Altitude difference is another possible cause of spatial heterogeneity in anaemia. According to [27], people residing at higher altitudes (greater than 1,000 meters (3,300 feet)) have higher $\mathrm{Hb}$ levels than those residing at sea level. This variation is due to the lower oxygen partial pressure at higher altitudes, a reduction in oxygen saturation of blood, and a compensatory increase in red blood cell production to ensure adequate oxygen supply to the tissues. Highland areas also have lower temperatures and thus are associated with less risk to malaria anaemia. Most areas in the north like Rumphi, Mzimba, Chitipa and part of Karonga are at high altitude, and this may explain their negative effect to anaemia. The effect of altitude on geographical variation of anaemia in this study may however be due to malaria-altitude relationship and not altitude- $\mathrm{Hb}$ level relationship as the later was accounted for by adjusting child $\mathrm{Hb}$ level for altitude according to DHS guide to statistics (see [27]). 


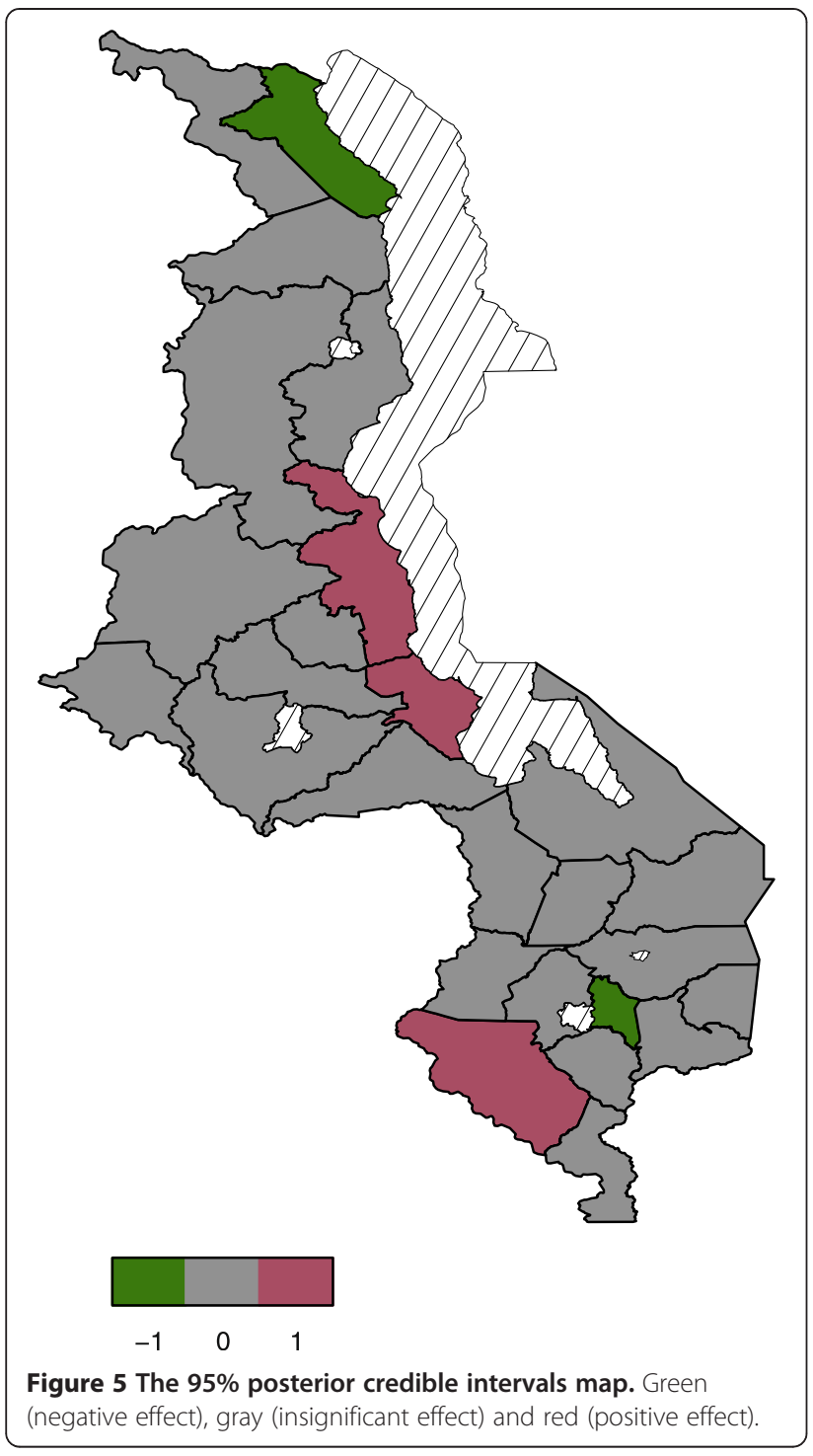

Regional nutritional disparities may also explain the spatial heterogeneity of childhood anaemia in Malawi. The cause of regional nutritional differences can be natural disasters like floods, and varying climatic conditions. Most valleys in Malawi, notably those of the Shire and Kasitu Rivers, and the southern end of Lake Malawi, are in rain shadows. Thus high risk of child anaemia in Chikhwawa, and Nsanje district may also be explained by floods from Shire River which annually destroys crops there by affecting the general nutrition of the area. Furthermore, these districts are in the Shire River basin which is a rain shadow area.

The fixed effects factors of childhood anaemia significant in this study are fever, wealth family of richest category, stunting and mother anaemia status. The finding of fixed effects factors generally confirm with what is known in the literature. The finding of fever agrees with that of [37] where fever had a positive effect. According

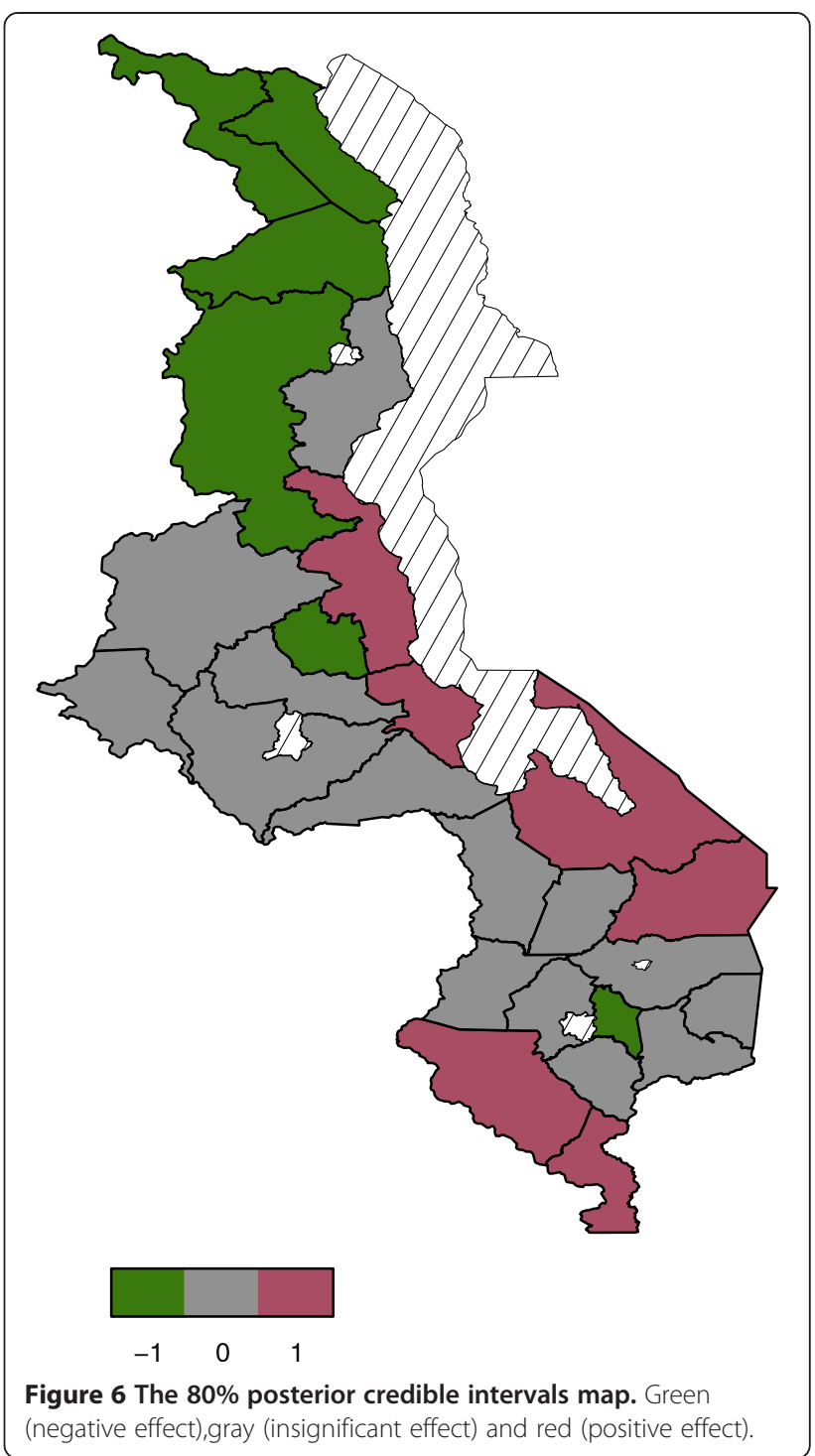

to [37], fever is a common symptom of acute and chronic inflammatory diseases, mostly infections, which have been associated with lower $\mathrm{Hb}$ levels. Existing anaemia is aggravated by underlying inflammation, which leads to alterations in iron homeostasis, impaired erythrocyte proliferation, blunted erythropoietin response, and decreased erythrocyte half-life. Moreover, several pro-inflammatory cytokines have been implicated in chronic inflammation anaemia, including interleukin(IL-) 1b, tumour necrosis factor-a (TNF-a), and IL-6.

Child age has been found to have non linear effect. Younger children are at higher risk of childhood anaemia compared to older children. This may be explained by the high demand for iron to ensure accelerated physical growth during the first year of life, and by the difficulty mothers and guardians have ensuring adequate iron consumption after the sixth month of life, when stored iron is depleted and iron needs must be met through feeding. 
Children of richest family have been found to have a reduced risk to childhood anaemia compared to the poorest children. This is probably due to good nutritious food the family affords, resulting into non anaemia. Mothers who are anaemic are also prone to have anaemic children. This finding is consistent with that of [10]. The association between child's haemoglobin level and maternal haemoglobin level may have multiple pathways. For example, maternal anaemia during pregnancy contributes to low birth weight and premature birth, both of which increase the risk of childhood anaemia. Low birth weight has been found to be risk factor of childhood anaemia by [13]. Severe maternal anaemia may also reduce breast milk iron content which can result in childhood anaemia.

Stunting positive effect on child anaemia can be due to chronic food shortage which results in reduced haemoglobin levels. Ngnie-Teta et al. [21] found a similar positive effect of stunting on childhood moderate to severe anaemia in Benin and Mali. Breast feeding had a linear effect which is consistent with most studies like that of [11]. Less months of breast feeding is associated with slightly high risk of anaemia and more months of breast feeding with less risk. Breast milk basically is said to have iron which is used in blood formation. Mother age had a non linear effect. Increased childhood anaemia for young mothers is probably due to young mothers requiring more iron for their growth there by affecting child haemoglobin level, and also elder mothers need more iron due to old age which can also affect child haemoglobin levels.

The study was not without weaknesses. The primary limitation of this study was its cross-sectional design. Despite the robustness of the analyses, control for the principal confounders, and the consistency of the main results with those of other studies on anaemia, no causal inference can be made. Moreover, because the analysis was based on an existing data set, we were limited to the use of variables found in the MDHS 2010. For instance, our study did not take into account the effect of early umbilical cord clamping after birth, which several studies have considered an important anaemia determinant [38].

\section{Conclusion}

In summary, there is evidence of residual spatial effect to childhood anaemia in Malawi. While government and non governmental organizations concerned with child health should be geared in treating childhood anaemia by focusing on known measurable factors like mother anaemia status, child age, mother age, family wealth, child fever and stunting which have been found to be significant in this study, attention should also be put to effects of unknown or unmeasured factors to childhood anaemia present at community level. Special attention to these unknown factors to childhood anaemia should be put to districts like, Nkhota-kota, Salima, Chikhwawa, Nsanje, Mangochi and Machinga that have shown significant positive spatial effects.

\section{Abbreviations}

AIC: Alkaike information creterion; BIC: Bayesian information criterion; Cl: Credible interval; EB: Empirical Bayes; GVC: Generalized cross validation; Hb: Haemoglobin; HIV: Human immune-deficiency virus; ICC: Intra-class correlation coefficient; MDHS: Malawi demographic health survey; NDVI: Normalized difference vegetation index; NSO: National statistics office; REML: Restricted maximum likelihood; SSA: Sub Saharan Africa; STAR: Structured additive regression.

\section{Competing interests}

The authors declare that they have no competing interests.

\section{Authors' contributions}

AN carried out the research and drafted the manuscript. LNK guided the research and reviewed the manuscript. Both authors read and approved the final manuscript.

\section{Acknowledgement}

We thank the Demographic and Health Survey program (www.measuredhs.com) initiated by the United States Agency for International Development (USAID) for providing the data that was used.

\section{Author details}

${ }^{1}$ Department of Mathematical Sciences, University of Malawi, Chancellor College, Zomba, Malawi. ${ }^{2}$ Department of Statistics and Population Studies, University of Namibia, Windhoek, Namibia.

Received: 3 December 2013 Accepted: 7 January 2015

Published online: 19 February 2015

\section{References}

1. WHO (2008). Worldwide prevalence of anaemia 1993-2005: WHO Global database on anaemia. WHO. Accessed on $2^{\text {nd }}$ August 2013 from http// www.who.int/vmnis/publications/anaemia_prevalenc.

2. Stevens GA, Finucane MM, De-Regil LM, Paciorek CJ, Flaxman SR, Branca $F$, et al. Global, regional, and national trends in haemoglobin concentration and prevalence of total and severe anaemia in children and pregnant and non-pregnant women for 1995-2011: a systematic analysis of population-representative data. Lancet Glob Health. 2013;1(1):e16.

3. NSO. Malawi DHS 2010-Final Report (English). 2011. Accessed on 1st June 2013 from http://www.measuredhs.com/publications.

4. English M, Waruiru C, Marsh K. Transfusion for respiratory distress in life-threatening childhood malaria. Am J Trop Med Hyg. 1996;55(5):525-30.

5. Phillips RE, Pasvol G. Anaemia of plasmodium falciparum malaria. Baillieres Clin Haematol. 1992:5:315-30.

6. Crawley J. Reducing the burden of anemia in infants and young children in malaria endemic countries of Africa: from evidence to action. Am J Trop Med Hyg. 2004;71:25-34.

7. Calis JCJ, Kamija SP, Faragher E, Benard J, Bates I, Cuevas LE, et al. Severe anaemia in Malawian children. N Engl J Med. 2008;2(358):888-99.

8. Sanou D, Ngnie-Teta I. Risk Factors for Anaemia in Preschool Children in Sub-Saharan Africa. 2012. Accessed on 7th January 2013 from http://www. intechopen.com/download/pdf

9. Tengco LW, Solon PR, Solon JA, Sarol JN, Solon FS. Determinants of anaemia among preschool children in Philippines. J Am Coll Nations. 2008;27(2):229-43.

10. Parischa S, Black J, Muthayya S, Shet A, Bhat V, Nagaraj S, et al. Determinants of anaemia among young children in rural India. Pediatrics. 2010;126:e140.

11. Kounnavong S, Sunahara T, Hashizume M, Okumura J, Moji K, Boupha B, et al. Anemia and related factors in preschool children in Southern Rural Lao Peoples Democratic Republic. Trop Med Health. 2011;39:95-103.

12. Fleming AF, Werblinska B. Anaemia in childhood in the guinea savana of Nigeria. Ann Trop Paediatr. 1982;2:161-73.

13. Cessie S, Verhoeff FH, Mengistie G, Kazembe P, Broadhead R, Brabin BJ. Changes in Haemoglobin levels in infants in Malawi: effects of low birth weight and fetal anemia. Arch Dis child Fetal Neonatal Ed. 2002;86:F182-7. 
14. Koissi MC, Högnäs G. Using WinBUGS to Study Family Frailty in Child Mortality, with an Application to Child Survival in Ivory Coast. Union African Population Studies. 2005;20:1

15. Hay SI, Guerra CA, Gething PW, Patil AP, Tatem AJ, Noor AM, et al. A world malaria map: plasmodium falciparum endemicity. PLoS Med. 2009;6:e48.

16. Piel FB, Patil AP, Howes RE, Nyangiri OA, Gething PW, Williams TN, et al. Global distribution of the sickle cell gene and geographical confirmation of the malaria hypothesis. Nat Commun. 2010;1:104.

17. Gayawan E, Arogundade ED, Adebayo SB. Possible determinants and spatial patterns of anaemia among young children in Nigeria: a Bayesian semi-parametric modeling. Int Health. 2014;6:35-45.

18. Koukounari A, Estambale BBA, Njagi JK, Cundill B, Ajanga A, Crudder C, et al. Relationship between anaemia and parasitic infections in Kenyan schoolchildren: a Bayesian hierarchical modelling approach. Int J Parasitol. 2008;38:1663-71.

19. Magalhães RJS, Clements ACA. Mapping the risk of anemia in preschool age children: the contribution of malnutrition, malaria, and helminth infections in West Africa. PLoS Med. 2011;8:6.

20. Messina JP, Mwandagalirwa K, Taylor SM, Emch M, Meshnick SR. Spatial and social factors drive anaemia in Congolese women. Health Place. 2013; 24(2013):54-64.

21. Ngnie-Teta I, Receveur O, Kuate-Defo B. Risk factors for moderate to severe anaemia among children in Benin and Mali: insights from a multilevel analysis. Food NutrBull. 2007:28(1):76-89.

22. Chaix B, Merlo J, Chauvin P. Comparison of a spatial approach with the multilevel approach for investigating place effects on health: the example of healthcare utilisation in France. J Epidemiol Community Health. 2005:59:517-26.

23. Kammann EE, Wand MP. Geoadditive models. J R Stat Soc C. 2003;52:1-18.

24. Kandala N, Fahrmeir L, Klasen S, Priebe J. Geo-additive models of childhood undernutrition in three sub-Saharan African countries. Popul Space Place. 2009;15(5):461-73

25. Kazembe LN, Neema I. Today, tomorrow, forever: a Bayesian ordered categories model for treatment seeking in febrile children. Int Sci Technol J Namibia. 2013;1(1):21-34

26. Pullan RL, Gitonga C, Mwandawiro C, Snow RW, Brooker SJ. Estimating the relative contribution of parasitic infections and nutrition for anaemia among school-aged children in Kenya: a subnational geostatistical analysis. BMJ Open. 2013;3:e001936.

27. Rutstein SO, Rojas J. Guide to DHS statistics: Demographic Healthy Survey Methodology. Measure DHS/ICF International. 2006. Accessed on 4th January 2013 from http://www.measuredhs.com.

28. Osei FB, Duker AA, Stern A. Bayesian structured additive regression modeling of epidemic cholera data: application to cholera. Med Res Methodol. 2012;12:118

29. Besag J, Kooperberg C. On conditional and intrinsic autoregression. Biometrika. 1995:82:733-46.

30. Kneib T, Lang S, Brezger A. Bayesian semiparametric regression based on mixed model methodology: a tutorial. Department of Statistics, University of Munich; 2004. Accessed on 8th July 2013 from http://www.uibk.ac.at.

31. Fahrmeir $L$, Kneib $T$, Lang $S$. Penalized structured additive regression for space-time data: a Bayesian perspective. Statistica Sinica. 2004;14:731-61.

32. Kneib T, Muller J, Hothorn T. Spatial smoothing techniques for the assessment of habitat suitability. Environ Ecol Stat. 2008;15:343-64.

33. Dzinjalamala F. Epidemology of malaria in Malawi: the Epidemology of Malawi. Malawi: College of Medicine; 2006. Accessed on 5th September, 2013 from http://www.medcol.mw/commhealth/publications.

34. Otto GF. A study of the moisture requirements of the eggs of the horse, the dog, human and pig ascarids. Am J Hyg. 1929:10:497-520.

35. Spindler $L A$. The relation of moisture to the distribution of human trichuris and ascaris. Am J Hyg. 1929;10:476-96.

36. Coffey D. Sanitation, the disease environment, and anaemia among young children. India: Rice Institute; 2013. Accessed on 3rd September, 2013 from http://www.riceinstute.org.

37. Konstantyner T, Oliveira TCR, Aguiar Carrazedo Taddei JA. Risk factors for Anaemia among Brazillian infants from the 2006 National Demographic Health Survey. Anaemia. 2012. Article Id 850681.

38. Hutton ES, Hassan ES. Late vs early clamping of the umbilical cord in full-term neonates: systematic review and meta-analysis of controlled trials. J Am Med Assoc. 2007:297(11):1241-52

\section{Submit your next manuscript to BioMed Central and take full advantage of:}

- Convenient online submission

- Thorough peer review

- No space constraints or color figure charges

- Immediate publication on acceptance

- Inclusion in PubMed, CAS, Scopus and Google Scholar

- Research which is freely available for redistribution 